\title{
Attenuating Nicotine Reinforcement and Relapse by Enhancing Endogenous Brain Levels of Kynurenic Acid in Rats and Squirrel Monkeys
}

\author{
Maria E Secci', Alessia Auber',3, Leigh V Panlilio', Godfrey H Redhi', Eric B Thorndike', Charles W Schindler', \\ Robert Schwarcz ${ }^{2}$, Steven R Goldberg' ${ }^{1, *}$ and Zuzana Justinova*,I \\ 'Preclinical Pharmacology Section, Behavioral Neuroscience Research Branch, Intramural Research Program, National Institute on Drug Abuse, \\ National Institutes of Health, Department of Health and Human Services, Baltimore, MD, USA; ${ }^{2}$ Maryland Psychiatric Research Center, \\ Department of Psychiatry, University of Maryland School of Medicine, Baltimore, MD, USA
}

\begin{abstract}
The currently available antismoking medications have limited efficacy and often fail to prevent relapse. Thus, there is a pressing need for newer, more effective treatment strategies. Recently, we demonstrated that enhancing endogenous levels of kynurenic acid (KYNA, a neuroinhibitory product of tryptophan metabolism) counteracts the rewarding effects of cannabinoids by acting as a negative allosteric modulator of $\alpha 7$ nicotinic receptors ( $\alpha 7 \mathrm{nAChRs).} \mathrm{As} \mathrm{the} \mathrm{effects} \mathrm{of} \mathrm{KYNA} \mathrm{on} \mathrm{cannabinoid} \mathrm{reward} \mathrm{involve} \mathrm{nicotinic} \mathrm{receptors,} \mathrm{in} \mathrm{the}$ present study we used rat and squirrel monkey models of reward and relapse to examine the possibility that enhancing KYNA can counteract the effects of nicotine. To assess specificity, we also examined models of cocaine reward and relapse in monkeys. KYNA levels were enhanced by administering the kynurenine 3-monooxygenase (KMO) inhibitor, Ro 61-8048. Treatment with Ro 6I-8048 decreased nicotine self-administration in rats and monkeys, but did not affect cocaine self-administration. In rats, Ro 6 I-8048 reduced the ability of nicotine to induce dopamine release in the nucleus accumbens shell, a brain area believed to underlie nicotine reward. Perhaps most importantly, Ro 61-8048 prevented relapse-like behavior when abstinent rats or monkeys were reexposed to nicotine and/or cues that had previously been associated with nicotine. Ro 61-8048 was also effective in monkey models of cocaine relapse. All of these effects of Ro 6I-8048 in monkeys, but not in rats, were reversed by pretreatment with a positive allosteric modulator of $\alpha 7 \mathrm{nAChRs}$. These findings suggest that $\mathrm{KMO}$ inhibition may be a promising new approach for the treatment of nicotine addiction.

Neuropsychopharmacology (2017) 42, 1619-1629; doi:10.1038/npp.2017.21; published online I March 2017
\end{abstract}

\section{INTRODUCTION}

Tobacco smoking is the largest preventable cause of morbidity and mortality, but most attempts to quit smoking are unsuccessful because of the addictive, rewarding effects of nicotine (Benowitz, 2009; Harvey et al, 2004). Existing treatments such as bupropion, varenicline, and nicotine replacement therapy are effective in some but not all smokers (Benowitz, 2009). New medications with different modes of action might be more effective or enhance the effectiveness of existing medications.

Like other addictive drugs, nicotine's ability to increase dopamine release in the mesolimbic area is believed to be

*Correspondence: Dr Z Justinova, Preclinical Pharmacology Section, Intramural Research Program, National Institute on Drug Abuse, $\mathrm{NIH}$, DHHS, 25 I Bayview Boulevard, Baltimore, MD 21224, USA, Tel: + I 443740 2522, Fax: + 443740 2733, E-mail: zuzana.justinova@nih.gov ${ }^{3}$ Current address: Department of Translational Pharmacology, Drug Discovery and Design, Aptuit, Verona, Italy.

Deceased.

Received 9 August 2016; revised 20 January 2017; accepted 23 January 2017; accepted article preview online 31 January 2017 critical for its rewarding effects (Corrigall et al, 1994). Nicotine produces these effects by binding to nicotinic acetylcholine receptors (nAChRs), essentially mimicking the agonist effects of endogenous acetylcholine. The rewarding effects of nicotine have largely been attributed to the $\beta 2$ subunit of nAChRs (Jackson et al, 2008; Orejarena et al, 2012; Picciotto et al, 1998; Tapper et al, 2004), but there is also evidence for involvement of the $\alpha 7$ subunit (Brunzell and McIntosh, 2012; Levin et al, 2009; Liu, 2014; Markou and Paterson, 2001). As these studies show that either activation or blockade of $\alpha 7 \mathrm{nAChRs}$ can disrupt nicotine self-administration, the role of these receptors appears to be complex. For example, $\alpha 4 \beta_{2} \mathrm{nAChRs}$ are high-affinity sites for nicotine compared with $\alpha 7 \mathrm{nAChRs}$, but $\alpha 4 \beta_{2} \mathrm{nAChRs}$ are quickly desensitized, whereas $\alpha 7 \mathrm{nAChRs}$ remain functional at much higher nicotine concentrations and 'may be important and play presently unappreciated roles in nicotine addiction and synaptic plasticity linked to associative learning' (Wooltorton et al, 2003).

Nicotinic receptors are also affected by another endogenous substance, kynurenic acid (KYNA) that acts as a negative allosteric modulator of $\alpha 7 \mathrm{nAChRs}$, decreasing the effects of 
acetylcholine at the receptor (Hilmas et al, 2001). KYNA is a metabolite of dietary tryptophan and is produced and released by astrocytes (Kiss et al, 2003). It occurs in mammalian brain at steady-state concentrations in the nanomolar to micromolar range (Moroni et al, 1988; Turski et al, 1988). In addition to $\alpha 7 \mathrm{nAChRs,} \mathrm{KYNA}$ interacts with other molecular targets, including the glycine co-agonist site of the NMDA receptor (Kessler et al, 1989), and, at higher concentrations, ionotropic glutamate receptors (Perkins and Stone, 1982). KYNA modulates neurotransmitter signaling in the brain (Amori et al, 2009; Beggiato et al, 2013; Carpenedo et al, 2001; Rassoulpour et al, 2005b; Wu et al, 2010; Zmarowski et al, 2009) and has antiexcitotoxic and anticonvulsant effects (Foster et al, 1984; Moroni et al, 2012; Stone and Darlington, 2013). In humans, abnormal KYNA levels have been observed in individuals with schizophrenia (Erhardt et al, 2001; Schwarcz et al, 2001) or neurodegenerative disorders such as Huntington's and Alzheimer's disease (Baran et al, 1999; Beal et al, 1990). Notably, exposure to nicotine leads to dose- and timedependent changes in cerebral KYNA synthesis (Rassoulpour et al, 2005a; Zielinska et al, 2009).

Through negative modulation of $\alpha 7 \mathrm{nAChRs}$, treatments that enhance endogenous levels of KYNA could potentially counteract the addictive effects of nicotine and other drugs that enhance mesolimbic dopamine. This idea is supported by neurochemical and electrophysiological studies in rats showing that treatments that increase KYNA levels in the brain: (1) block nicotine-induced activity of dopamine neurons in the substantia nigra (Erhardt et al, 2000); (2) block nicotine-induced increases in cortical glutamate (Konradsson-Geuken et al, 2009); and (3) decrease the amplitude of nicotine-evoked glutamatergic transients (Koshy Cherian et al, 2014). We recently showed that enhancing endogenous KYNA counteracts reward-related behavioral and neurochemical effects of THC (the main active constituent of marijuana) in rodents and non-human primates, and that these effects are due to the actions of KYNA as a negative allosteric modulator of $\alpha 7 \mathrm{nAChRs}$ (Justinova et al, 2013). However, the effects of such treatments have not been evaluated previously in animal models of nicotine reward and relapse or mesolimbic dopamine release.

In the present study, KYNA levels were enhanced by inhibiting kynurenine 3-monooxygenase (KMO) that shunts the kynurenine metabolism pathway toward increased production of KYNA. As in our cannabinoid study (Justinova et al, 2013), this was accomplished with the potent, selective KMO inhibitor, Ro 61-8048 (Röver et al, 1997). We examined the effects of Ro 61-8048 on: (1) nicotine self-administration in squirrel monkeys and rats to model reward (Goldberg et al, 1981; Rose and Corrigall, 1997); (2) priming-induced and cue-induced reinstatement of nicotine seeking in monkeys and rats to model relapse; and (3) nicotine-induced elevation of dopamine levels in the nucleus accumbens shell (NAcS) of rats (Mascia et al, 2011). In monkeys, we also studied the effects of Ro 61-8048 on cocaine self-administration and reinstatement. In all experiments, the involvement of $\alpha 7 \mathrm{nAChRs}$ in the effects of Ro 618048 was assessed by determining whether the effects were blocked by PNU120596, a selective positive allosteric modulator of $\alpha 7 \mathrm{nAChRs} \mathrm{(Hurst} \mathrm{et} \mathrm{al,} \mathrm{2005).}$

\section{MATERIALS AND METHODS}

\section{Subjects}

Male Sprague-Dawley rats (Charles River Laboratories, Wilmington, MA; 300-350 g) and male squirrel monkeys (Saimiri sciureus; $0.9-1.1 \mathrm{~kg}$ ) were housed in temperatureand humidity-controlled rooms with unlimited access to water. Self-administration rats were singly housed and fed $20 \mathrm{~g}$ chow/day. Microdialysis rats were housed in groups of two with unlimited food. Monkeys were individually housed and ( $\sim 2 \mathrm{~h}$ after the session) fed high protein monkey diet biscuits (Lab Diet 5045, PMI Nutrition International, Richmond, IN) and Banana Softies (Bio-Serv, Frenchtown, NJ) to maintain stable body weights. Fresh fruit, vegetables, and environmental enrichment were also provided daily. The facilities were fully accredited by the Association for Assessment and Accreditation of Laboratory Animal Care (AAALAC). All procedures were conducted in accordance with the Guidelines of the National Research Council.

\section{Drugs}

(-)-Nicotine hydrogen tartrate (Sigma-Aldrich, St Louis, $\mathrm{MO}$ ) was dissolved in saline ( $\mathrm{pH}$ adjusted to 7.0), with doses expressed as the base. (-)-Cocaine hydrochloride (NIDA Drug Supply Program, Bethesda, MD) was dissolved in saline, with doses expressed as the salt. The KMO inhibitor Ro 61-8048 (3,4-dimethoxy-[-N-4-(nitrophenyl)thiazol-2yl]-benzenesulfonamide; Sai Advantium Pharma, Hyderabad, India) was dissolved in 5-6\% Tween-80 in saline and injected $40 \mathrm{~min}$ before the session (behavioral experiments) or before nicotine (microdialysis experiments) unless noted otherwise. The injection volume of Ro $61-8048$ was $0.5 \mathrm{ml} / \mathrm{kg}$ in monkeys and $1 \mathrm{ml} / \mathrm{kg}$ in rats. PNU120596 (N-(5-chloro2,4-dimethoxyphenyl)-N'-(5-methyl-3-isoxazolyl)-urea; Tocris Bioscience, Minneapolis, $\mathrm{MN}$ ) was dissolved in saline containing 5\% ethanol and 5\% cremophor EL. PNU120596 was injected $50 \mathrm{~min}$ before the session in monkeys or $60 \mathrm{~min}$ before the session in rats. The doses and pretreatment times for PNU120596 and Ro 61-8048 were based on those used in our previous study (Justinova et al, 2013).

\section{Intravenous Self-Administration of Nicotine by Rats}

The general procedure has been described previously (Scherma et al, 2008). Briefly, rats $(n=17)$ were surgically implanted with a catheter in the right jugular vein 6-7 days before starting self-administration training. During daily $2 \mathrm{~h}$ sessions, responding in the active nose-poke hole (on a fixedratio one schedule (FR1)) produced nicotine $(30 \mu \mathrm{g} / \mathrm{kg})$ and pulsed the houselight $(5 \mathrm{~Hz})$ for a $20 \mathrm{~s}$ timeout. Responses in the other, inactive, hole had no scheduled consequences. After stabilization of daily intake (no more than 15\% variation from the preceding session for 3 sessions), the effects of pretreatment with vehicle, 30, and $100 \mathrm{mg} / \mathrm{kg}$ of Ro 61-8048 (i.p.) were tested for three consecutive sessions each, and with $56 \mathrm{mg} / \mathrm{kg}$ Ro 61-8048 for one session. The dose of $56 \mathrm{mg} / \mathrm{kg}$ was always tested first and followed by 30 or $100 \mathrm{mg} / \mathrm{kg}$ doses in mixed order. PNU120596 (1 mg/kg, i.p.) was then tested alone and in combination with $100 \mathrm{mg} / \mathrm{kg}$ Ro 61-8048 for three consecutive sessions each. The animals returned to baseline between each treatment until the 
conditions for further testing were met. Because of loss of catheters during the study, not all treatments were tested in all rats.

\section{Combined Drug- and Cue-Induced Reinstatement of Nicotine Seeking in Rats}

The general procedure has been described previously (Mascia et al, 2011). Experimentally naive rats were trained to self-administer nicotine as described above and then placed under extinction conditions, in which responding had no scheduled consequences. When responding decreased to $<10$ responses per session for three consecutive days $(n=10)$, reinstatement testing was effected by pretreatment with vehicle or Ro 61-8048 (100 mg/kg i.p.) $40 \mathrm{~min}$ before a nicotine $(0.2 \mathrm{mg} / \mathrm{kg}$ s.c., $10 \mathrm{~min}$ before the session) or vehicle priming injection. The role of $\alpha 7 \mathrm{nAChRs}$ in the effects of Ro 61-8048 was then studied by pretreating with PNU120596 (1 mg/kg) before nicotine prime combined with Ro 61-8048 or its vehicle. PNU120596 was also given before a vehicle prime. Nicotine priming-induced reinstatement was always tested first, followed by other treatments in pseudorandom order. The animals returned to the extinction baseline between treatments, and all treatments were tested in all animals. During reinstatement sessions, i.v. injections were not delivered, but the visual cues that had previously been associated with nicotine delivery were presented contingent on responding. Thus, the nicotine reinstatement test in rats involved a combination of nicotine priming and reexposure to nicotine-associated cues that produces a highly robust reinstatement effect (Mascia et al, 2011; Shoaib, 2006).

\section{Intravenous Self-Administration in Squirrel Monkeys}

The general procedure and apparatus have been described previously (Justinova et al, 2003). At the start of each $1 \mathrm{~h}$ session, the houselight was extinguished, and a green cue light was presented to signal availability of the drug. After that, every 10 lever responses (FR10) produced a $30 \mu \mathrm{g} / \mathrm{kg}$ injection of nicotine (subjects 441,577, 572, 431, 4903, and 4912) or cocaine (subjects 70F7, 39B, and 2F19), extinguished the green cue light, and illuminated an amber cue light for $2 \mathrm{~s}$. Each injection was followed by a $60 \mathrm{~s}$ timeout, during which the chamber was dark, and lever presses had no programmed effect. In the nicotine-trained monkeys $(n=3)$, each dose of Ro 61-8048 (10, 20, and $30 \mathrm{mg} / \mathrm{kg}$; i.m., $40 \mathrm{~min}$ before the session) was studied for three consecutive sessions and preceded and followed by at least three sessions when vehicle was given i.m. before the session. After establishing the effects of Ro 61-8048 on selfadministration of the training dose of nicotine, we determined whether Ro 61-8048 shifted the nicotine doseresponse function $(n=3)$. A selected dose of Ro 61-8048 $(20 \mathrm{mg} / \mathrm{kg})$ was tested for one session at each of three doses of nicotine (studied in the following order: 30, 100, and $10 \mu \mathrm{g} / \mathrm{kg} /$ injection), with 3-5 sessions of vehicle pretreatment preceding each test. To study the role of $\alpha 7 \mathrm{nAChRs,}$ PNU120596 $(1 \mathrm{mg} / \mathrm{kg})$ or vehicle was injected i.m. before Ro 61-8048 (20 mg/kg) before nicotine self-administration sessions. In the cocaine-trained group $(n=3)$, Ro 61-8048 $(30 \mathrm{mg} / \mathrm{kg})$ was tested under self-administration and reinstatement procedures that paralleled the nicotine group.

\section{Priming-Induced Reinstatement of Drug Seeking in Squirrel Monkeys}

After completion of the experiments described above and two additional weeks of nicotine $(n=4)$ or cocaine $(n=3)$ self-administration, extinction and priming-induced reinstatement tests were conducted. During extinction sessions before priming tests, saline was delivered instead of nicotine or cocaine, but visual cues were presented as they were during normal self-administration sessions. When responding in extinction reached a low, stable level $(<100$ lever presses per session that equals $<10$ vehicle injections per session), a reinstatement test was conducted by giving a nicotine or cocaine priming injection $(0.1 \mathrm{mg} / \mathrm{kg}$, i.v., immediately before the session) after pretreatment with vehicle or PNU120596 ( $1 \mathrm{mg} / \mathrm{kg}$, i.m., $50 \mathrm{~min}$ before the session) followed by vehicle or Ro $61-8048(20 \mathrm{mg} / \mathrm{kg}$, i.m., $40 \mathrm{~min}$ before the session). Pretreatments were given in the home cage, and priming injections were given in the training chamber. The nicotine priming-induced reinstatement was always tested first, followed by the treatments in pseudorandom order. Each test was performed for a single session, except for the priming-induced reinstatement tests with vehicle pretreatment that were performed 2 times during the testing sequence. Each test was preceded by an extinction session in which vehicle (i.m.) and saline (i.v.) injections were given before the session.

\section{Cue-Induced Reinstatement of Drug Seeking in Squirrel Monkeys}

After completion of the priming-induced reinstatement study, monkeys were returned to the baseline nicotine $(n=3)$ or cocaine $(n=3)$ self-administration condition for 2 weeks. Then, extinction was conducted in which intravenous injections and the injection-paired visual cue (ie, the amber cue light) were discontinued and under these conditions the rates decreased to $<100$ lever presses within $2-3$ sessions. Cue-induced reinstatement was conducted by giving response-contingent presentation of the previously drug-paired visual and interoceptive cues (ie, amber cue light and i.v. saline) on an FR10 schedule with vehicle pretreatment. Ro 61-8048 (20 mg/kg, i.m., 40 min before the session) and PNU120596 ( $1 \mathrm{mg} / \mathrm{kg}$, i.m., $50 \mathrm{~min}$ before the session) alone as well as their combination were each tested in one cue-induced reinstatement test, preceded by 1-2 extinction sessions during which the vehicles were given before the session. Ro 61-8048 and PNU120596 alone were also given before extinction sessions. The cue-induced reinstatement was always tested first, followed by the treatments in pseudorandom order. Cue-induced reinstatement was tested 3 times in total during the testing sequence.

\section{In Vivo Microdialysis in Freely Moving Rats}

The general procedure and apparatus have been described previously (Solinas et al, 2006). Rats $(n=46)$ were surgically implanted with a concentric dialysis probe aimed at the NAcS (anterior $+2.0 \mathrm{~mm}$, lateral $\pm 1.1 \mathrm{~mm}$ from bregma, and vertical $-8.0 \mathrm{~mm}$ from dura) (Paxinos and Watson, 2005). The next day, Ringer's solution (147.0 mM NaCl, $2.2 \mathrm{mM}$ $\mathrm{CaCl}_{2}, 4.0 \mathrm{mM} \mathrm{KCl}$ ) was delivered at a constant flow rate of 

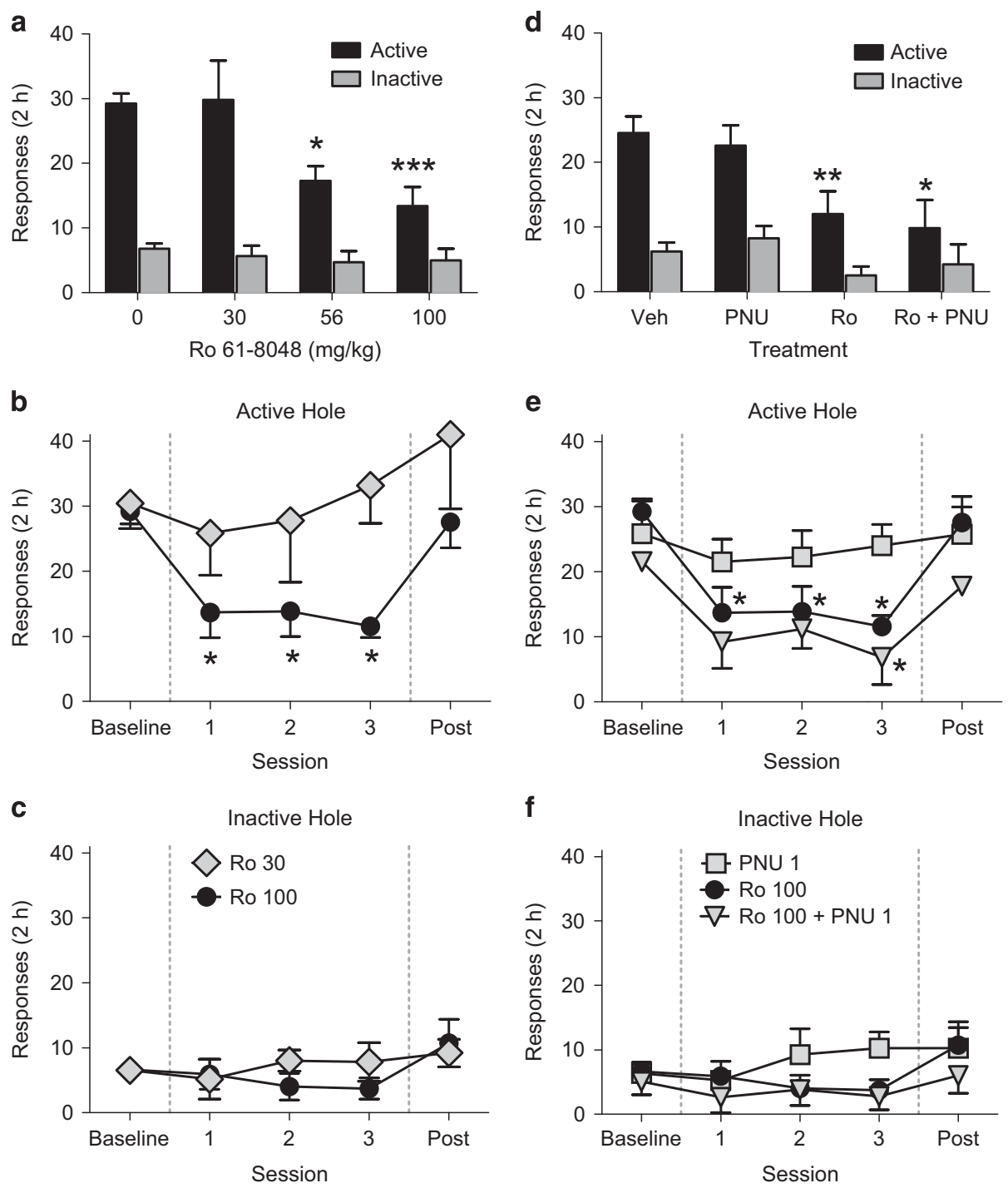

Figure I The KMO inhibitor Ro 6I-8048 dose-dependently reduces nicotine self-administration under a fixed-ratio (FRI) schedule in rats. (a-c) Nosepoke responses in active and inactive holes during single-session ( $2 \mathrm{~h}$ ) nicotine self-administration (30 $\mathrm{kg} / \mathrm{kg} / \mathrm{injection}$ ) tests with vehicle or Ro $6 \mathrm{I}-8048$ (30, 56 , and $100 \mathrm{mg} / \mathrm{kg}$, i.p.) pretreatment $40 \mathrm{~min}$ before the session $(n=14)$. (a) The first day of treatment with Ro $61-8048$ is shown. Responses in active (b) and inactive $(c)$ holes per session $(n=12)$ are shown during 3 consecutive days of pretreatment with 30 or I00 mg/kg of Ro 6I-8048 (sessions I-3) compared with vehicle treatment (baseline). Pretreatment with PNUI20596 (I mg/kg, i.p., 60 min before the session) did not prevent the effect of Ro $61-8048$ $(100 \mathrm{mg} / \mathrm{kg}$ ) on nicotine self-administration. (d-f) Responses in active and inactive holes during a $2 \mathrm{~h}$ session are shown during 3-day pretreatment with vehicle $(n=8)$, PNUI $20596(n=4)$, Ro 6 I-8048 ( $n=3)$, or a combination of Ro 6I-8048 and PNUI20596 ( $n=4)$ (d). Responses in active (e) and inactive (f) holes are also shown during 3 consecutive days of pretreatment with Ro 6 I-8048 ( $n=10)$, PNUI 20596 ( $n=4)$, or a combination of Ro 6 I-8084 and PNUI 20596 (sessions I-3; $n=12$ ) compared with vehicle treatment (baseline). All data are mean \pm SEM. *Significantly different from vehicle $(0 \mathrm{mg} / \mathrm{kg}$ Ro $6 \mathrm{I}-8048$ or baseline), Tukey's test, ${ }^{*} p<0.05$, ** $p<0.0$ I, **** $p<0.00$ I. Ro, Ro 6I-8048; PNU, PNUI 20596.

$1.0 \mu \mathrm{l} / \mathrm{min}$, starting $90 \mathrm{~min}$ before the first sample. Dialysate samples $(20 \mu \mathrm{l}$ per sample) were collected every $20 \mathrm{~min}$ and immediately analyzed by a high-performance liquid chromatography system coupled to electrochemical detection to quantify dopamine. Treatments were given after stable dopamine values $(<15 \%$ variability) were obtained for at least three consecutive samples. Ro 61-8048 (100 mg/kg, i.p.) was injected $40 \mathrm{~min}$ before nicotine $(0.4 \mathrm{mg} / \mathrm{kg}$, s.c.) or vehicle. PNU120596 ( 1 and $3 \mathrm{mg} / \mathrm{kg}$ ) was injected i.p. $60 \mathrm{~min}$ before nicotine or vehicle. Probe placements were verified histologically after each experiment.

\section{Data Analysis}

Rodent behavioral data were analyzed using Proc Mixed (SAS Institute, Cary, NC) with Tukey-Kramer comparisons. Variables were drug treatment and response hole (active $v s$ inactive). For maintenance experiments, the mean for the 3 days of each test were compared with the mean from the previous three baseline sessions. For illustration of effects over consecutive sessions, additional analyses were performed comparing each test session with the mean of the three preceding baseline sessions. Dopamine levels from the microdialysis procedure were expressed as a percentage of 


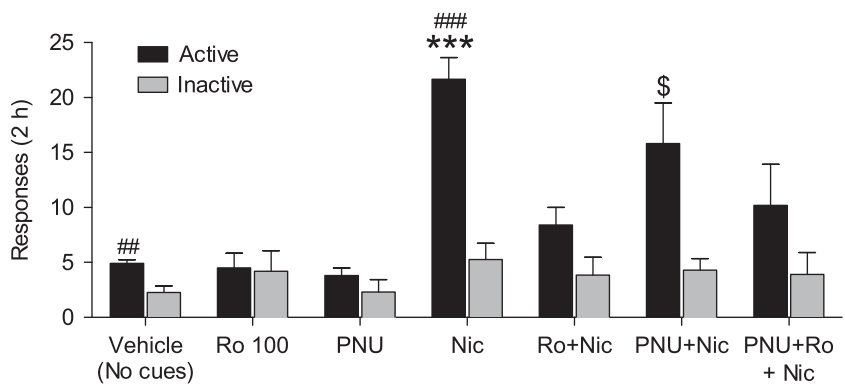

Figure 2 Ro 6l-8048 blocks reinstatement of extinguished nicotine seeking in rats. Ro $61-8048(100 \mathrm{mg} / \mathrm{kg}$, i.p., $40 \mathrm{~min}$ before the session) blocked the reinstating effect of combined nicotine priming $(0.2 \mathrm{mg} / \mathrm{kg}$, s.c., $10 \mathrm{~min}$ before the session) and reintroduction of response-contingent presentation of visual cues that were previously associated with nicotine injections. PNUI 20596 (I mg/ $/ \mathrm{kg}$, i.p., $60 \mathrm{~min}$ before the session) failed to block the effect of Ro 6I-8048 on reinstatement. Responses in active and inactive holes per $2 \mathrm{~h}$ sessions are shown. Bars represent means \pm SEM $(n=10$ in all groups). *Significantly different from vehicle session (saline prime and no cues), Ro 100, PNU, and Ro+Nic (active responding); \$significantly different from the vehicle session; " significant difference between active and inactive responding, Tukey's test, $\$ p<0.05$; $\# \#<0.01$; **** or \#\#\# $<0.00$ I. Nic, nicotine; Ro, Ro 6I-8048; PNU, PNUI 20596

basal level and analyzed with treatment and time as factors, and Tukey's post hoc tests were used to analyze significant main effects. Primate self-administration and reinstatement data were analyzed with repeated measures ANOVAs (SigmaPlot) with Tukey's post hoc tests.

\section{RESULTS}

\section{Effect of Ro 61-8048 on Nicotine Self-Administration in Rats}

Ro 61-8048 (56 and $100 \mathrm{mg} / \mathrm{kg}$ ) significantly decreased ongoing nicotine self-administration (Figure 1a; interaction of response hole (active $v s$ inactive) and treatment: $\left.\mathrm{F}_{3,21}=10.06, p<0.001\right)$. Paired comparisons showed that responding in the active hole was significantly decreased by both doses of the KMO inhibitor, but that responding in the inactive hole was not significantly affected. The effect of Ro $61-8048(100 \mathrm{mg} / \mathrm{kg})$ was consistent over the 3 days of treatment (Figure $1 \mathrm{~b}$ and c). Treatment with PNU120596 $(1 \mathrm{mg} / \mathrm{kg})$ failed to block the effects of Ro 61-8048 when tested in a subset of four rats; the interaction of hole and treatment was again significant (Figure $1 \mathrm{~d} ; \mathrm{F}_{3,8}=6.38$, $p<0.05)$, with both Ro 61-8048 $(100 \mathrm{mg} / \mathrm{kg})$ alone and the combination of Ro $61-8048(100 \mathrm{mg} / \mathrm{kg})$ with PNU120596 consistently decreasing nicotine self-administration (Figure 1d) over the 3 days of treatment (Figure 1e and f).

\section{Effect of Ro 61-8048 on Combined Drug Priming and Cue-Induced Reinstatement in Rats}

Nicotine seeking was reinstated by noncontingent priming with i.v. nicotine $(0.2 \mathrm{mg} / \mathrm{kg}, 10 \mathrm{~min}$ before the session) plus reexposure to response-contingent visual cues that had previously been associated with nicotine (Figure 2, 'Nic' condition). Ro 61-8048 (100 mg/kg) significantly blocked this reinstatement (interaction of treatment and hole,
$\left.\mathrm{F}_{6,54}=8.41, p<0.001\right)$. Neither the $\alpha 7 \mathrm{nAChR}$-positive allosteric modulator PNU120596 (1 mg/kg) nor Ro 61-8048 $(100 \mathrm{mg} / \mathrm{kg})$ reinstated nicotine seeking when given alone, and PNU120596 did not block the reinstating effect of nicotine (Figure 2, 'PNU+Nic'). However, pretreatment with PNU120596 did not fully prevent Ro 61-8048 from blocking the effect of nicotine (Figure 2, 'PNU+Ro+Nic'), making it uncertain whether the effects of Ro 61-8048 on nicotineinduced reinstatement were due to negative allosteric modulation of $\alpha 7 \mathrm{nAChRs}$ in rats.

\section{Effect of Ro 61-8048 on Nicotine Self-Administration and Reinstatement of Nicotine Seeking in Squirrel Monkeys}

Under baseline conditions (vehicle pretreatment), high numbers of self-administered nicotine injections (Figure $3 \mathrm{a}$ ) and high rates of lever responding (Figure $3 \mathrm{~b}$ ) were maintained at the $30 \mu \mathrm{g} / \mathrm{kg}$ dose of nicotine. At all three doses tested (10, 20,30 mg/kg), Ro 61-8048 significantly reduced the number of nicotine injections (Figure 3a, $\left.\mathrm{F}_{3,12}=18.66, p<0.01\right)$ and the self-administration response rate (Figure $3 b, F_{3,12}=518.58, p<0.001$ ) compared with vehicle pretreatment. There was no significant difference in the effects between the three doses of Ro 61-8048 (injections: all $p$ 's $>0.05$; response rates: all $p$ 's $>0.05$ ). When Ro 61-8048 treatment was discontinued, both response rate and the number of injections rapidly recovered to baseline levels. The attenuation of nicotine self-administration by Ro 61-8048 $(20 \mathrm{mg} / \mathrm{kg})$ was completely reversed by pretreatment with $1 \mathrm{mg} / \mathrm{kg}$ of PNU120596 (Figure 3c, injections: $\mathrm{F}_{4,16}=122.9$, $p<0.001$; Figure 3d, response rates: $\mathrm{F}_{4,16}=122.9, p<0.001$ ), indicating involvement of $\alpha 7 \mathrm{nAChRs}$ in the effects of Ro 61-8048. Pretreatment with Ro 61-8048 (20 mg/kg) also produced a clear downward shift of the nicotine doseresponse functions (Figure 3e, injections: $\mathrm{F}_{1,4}=96.47$, $p<0.01$; Figure 3f, response rates: $F_{1,4}=67.99, p<0.05$ ), indicating attenuation of reinforcing effects of nicotine.

Nicotine priming-induced reinstatement. When saline was substituted for i.v. nicotine in the self-administration procedure (ie, extinction), the monkeys' responding decreased to very low levels (Figure 4a). Noncontingent priming injections of nicotine $(0.1 \mathrm{mg} / \mathrm{kg}$, i.v. $)$ reinstated nicotine seeking (Figure $4 \mathrm{a}$ ), but this effect was significantly blocked by pretreatment with Ro 61-8048 $(20 \mathrm{mg} / \mathrm{kg})$ (Figure $4 \mathrm{a}$, lever presses: $\mathrm{F}_{6,18}=46.90, p<0.001$ ). The effect of Ro $61-8048$ was reversed by pretreatment with $1 \mathrm{mg} / \mathrm{kg}$ PNU120596 $(p<0.01)$ - a dose that by itself did not affect nicotine-primed reinstatement. Neither Ro 61-8048 (20 mg/ $\mathrm{kg})$ nor PNU120596 $(1 \mathrm{mg} / \mathrm{kg})$ reinstated nicotine seeking when given with a vehicle prime.

Cue-induced reinstatement. During extinction, when responding no longer produced nicotine or its associated visual and interoceptive/injection-related cues, response rates decreased to very low levels (Figure $4 \mathrm{~b}$ ). Reintroduction of response-dependent visual and interoceptive cues (amber light plus saline injection) reinstated nicotine seeking (Figure $4 \mathrm{~b}$ ). Pretreatment with Ro 61-8048 (20 mg/kg) significantly decreased cue-induced reinstatement (Figure $4 \mathrm{~b}: \mathrm{F}_{6,12}=87.83$, 
$p<0.001)$. This effect of Ro 61-8048 was reversed by pretreatment with PNU120596 $(p<0.01)$. PNU120596 (1 mg/ $\mathrm{kg}$ ) alone did not affect cue-induced reinstatement of nicotine seeking. In addition, neither Ro 61-8048 (20 mg/kg) alone nor PNU120596 (1 mg/kg) alone reinstated extinguished drug seeking when injected before the extinction session. a
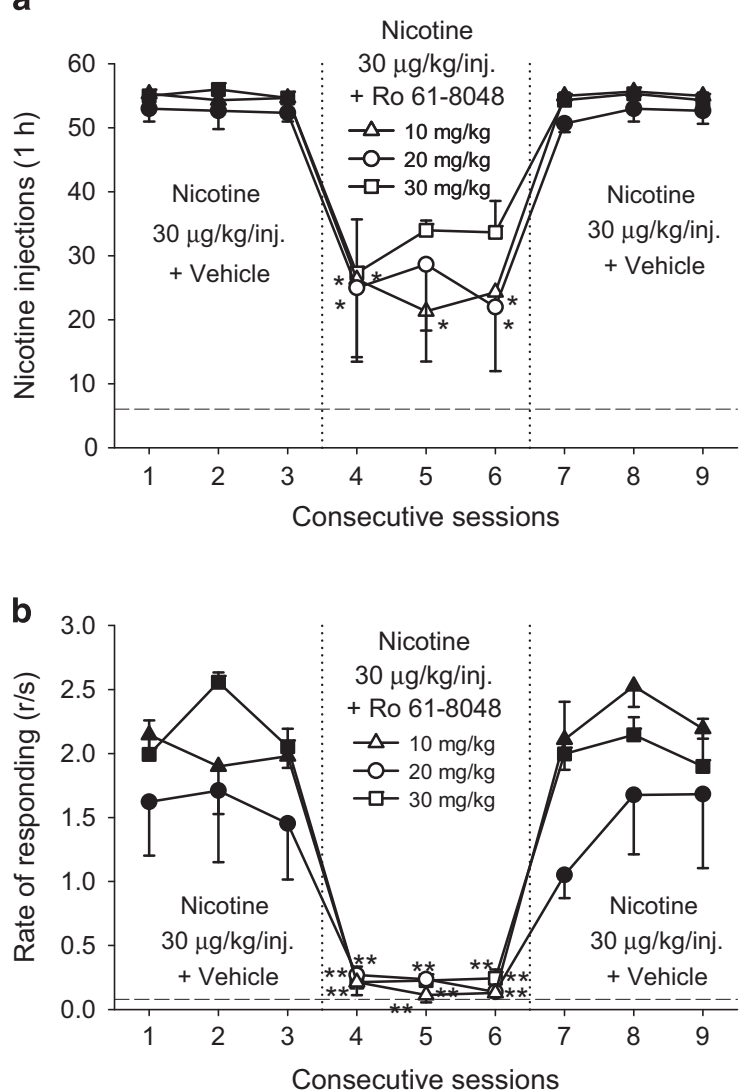

e
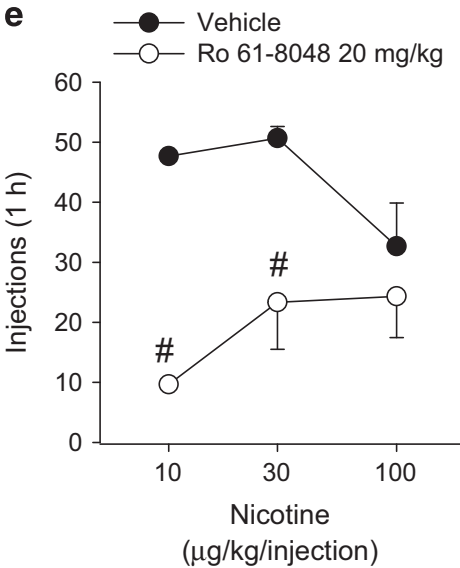
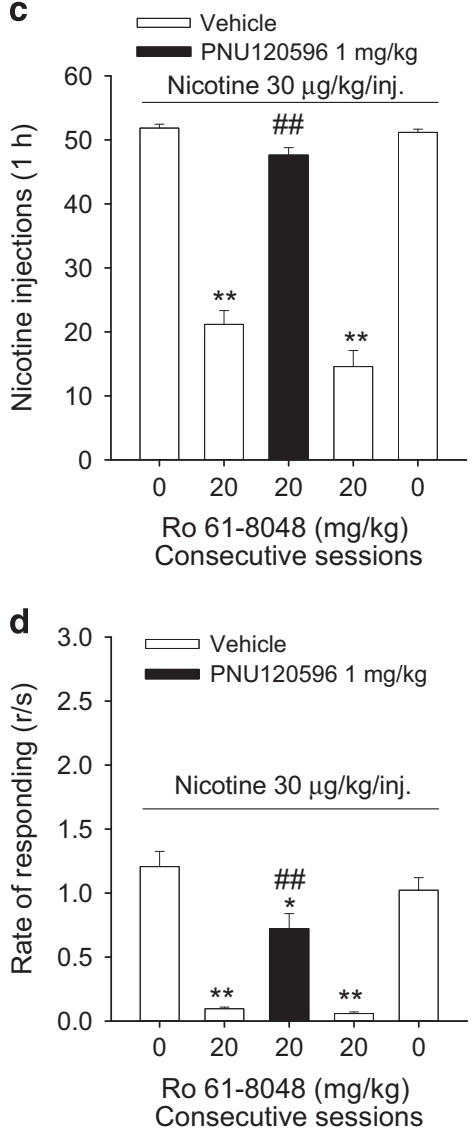

f

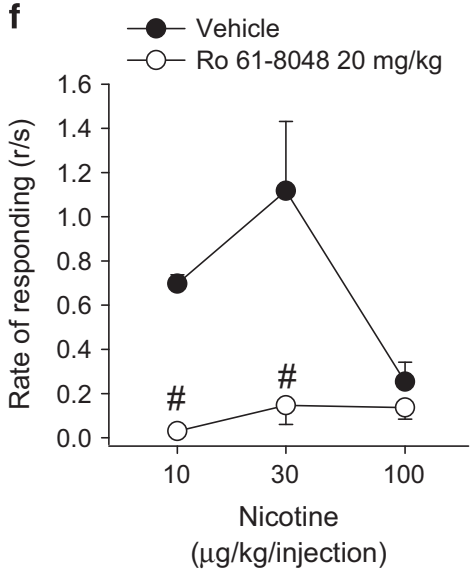

Figure 3 Ro 6I-8048 reduces nicotine self-administration under FRIO schedule in squirrel monkeys. (a, b) The 3-day treatment with Ro 6I-8048 (I0, 20, and $30 \mathrm{mg} / \mathrm{kg}$, i.m., $40 \mathrm{~min}$ before sessions 4-6) significantly decreased the number of nicotine (30 $\mathrm{kg} / \mathrm{kg}$ ) injections self-administered during I h sessions (a) and the overall response rate (b). *Significantly different from the average of three sessions with vehicle treatment (sessions I-3), Tukey's test. (c, d) The effect of Ro $61-8048(20 \mathrm{mg} / \mathrm{kg})$ on nicotine self-administration was reversed by pretreatment with PNUI20596 (I mg/ $/ \mathrm{kg}$, i.m., $50 \mathrm{~min}$ before the session). The effects of single-session pretreatment with vehicle, Ro 6I-8048 (20 mg/kg), and the combination of Ro 6I-8048 and PNUI 20596 on the number of nicotine $(30 \mathrm{Hg} / \mathrm{kg}$ ) injections (c) and rates of responding (d) are shown over consecutive sessions. *Significantly different from 'Vehicle+0 mg/kg Ro 6I-8048' pretreatment'; " significantly different from 'Vehicle+20 mg/kg Ro 6I-8048' pretreatment. (e, f) Ro 6I-8048 shifted nicotine self-administration dose-response curves downward in squirrel monkeys. Number of nicotine injections (e) self-administered per I h session and overall rates of responding ( $f$ ) are shown after single i.m. pretreatment with Ro $61-8048(20 \mathrm{mg} / \mathrm{kg})$ or vehicle. Numbers of injections and rates of responding are presented as a function of injection dose of nicotine. " Significantly different from vehicle treatment within each nicotine dose, Tukey's test. The symbols and bars represent the mean \pm SEM $(n=3$ in all parts of the Figure). The dashed line (a, b) represents the level of vehicle extinction. * or ${ }^{\#}<0.05$, ** or \#\# $p<0.0$ l. 
a Nicotine priming-induced reinstatement

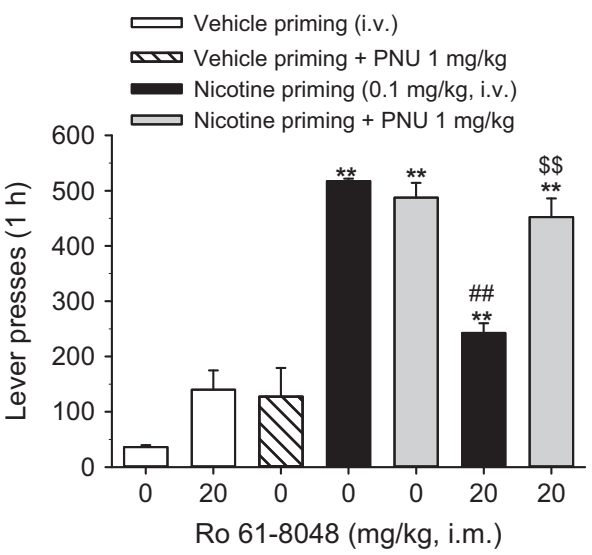

b

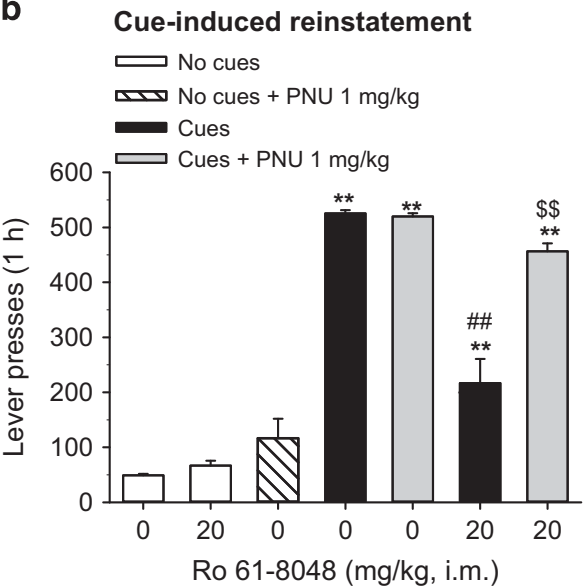

Figure 4 Ro 61-8048 blocks reinstatement of extinguished nicotine seeking in squirrel monkeys. Vehicle (0 mg/kg), Ro $61-8048$ (20 mg/ $/ \mathrm{kg})$, and PNUI20596 (I mg/ $/ \mathrm{kg})$ were administered alone or in combination before: priming with vehicle or nicotine $(0.1 \mathrm{mg} / \mathrm{kg})$ i.v. injection $(\mathrm{a}, \mathrm{n}=4)$ or reintroduction of nicotine-associated cues (b, $n=3$ ). 'Vehicle priming+0 mg/kg Ro 6I-8048' and 'No cues+0 mg/kg Ro 6I-8048' bars represent the average of 5-7 extinction sessions preceding the test sessions. 'Nicotine priming+0 mg/kg Ro 6I-8048' bars represent the average from two tests. 'Cues+0 mg/ $/ \mathrm{kg}$ Ro 618048' bars represent the average from three tests. *Significantly different from 'Vehicle priming+0 mg/kg Ro 6I-8048' or 'No cues+0 mg/kg Ro 6I-8048'; " significantly different from 'Nicotine priming+0 mg/kg Ro 6I-8048' or 'Cues+0 mg/kg Ro 6I-8048'; 'significantly different from 'Nicotine priming+20 mg/kg Ro 61-8048' or 'Cues+20 mg/kg Ro 61-8048', Tukey's test. ** or ${ }^{\# \# ~ o r ~}{ }^{\$ \$} p<0.01$. The bars represent mean \pm SEM. PNU, PNUI 20596.

\section{Effect of Ro 61-8048 on Cocaine Self-Administration and Reinstatement of Cocaine Seeking in Squirrel Monkeys}

In a separate group of monkeys, we found that Ro 61-8048 $(30 \mathrm{mg} / \mathrm{kg})$ did not affect self-administration of cocaine $\left(30 \mu \mathrm{g} / \mathrm{kg} /\right.$ injection) (Figure $5 \mathrm{a}$, injections: $\mathrm{F}_{3,6}=0.56$, $p>0.05$; Figure $5 \mathrm{~b}$, response rates: $\left.\mathrm{F}_{3,6}=0.58, p>0.05\right)$, extending our earlier finding (Justinova et al, 2013) that a lower dose of Ro $61-8048(20 \mathrm{mg} / \mathrm{kg})$ did not affect cocaine self-administration, even though it decreased THC self-administration.

Cocaine priming-induced reinstatement. Cocaine priming injections $(0.1 \mathrm{mg} / \mathrm{kg}$, i.v. $)$ reinstated cocaine seeking (Figure 5c). Pretreatment with Ro 61-8048 (20 mg/kg) significantly decreased cocaine-primed reinstatement (Figure $5 \mathrm{c}$ : $\left.\mathrm{F}_{6,12}=26.79, p<0.001\right)$. This effect of Ro 61-8048 was reversed by pretreatment with $1 \mathrm{mg} / \mathrm{kg}$ PNU120596 that by itself did not affect cocaine-primed reinstatement. When injected before vehicle priming, neither $20 \mathrm{mg} / \mathrm{kg}$ Ro 61-8048 nor $1 \mathrm{mg} / \mathrm{kg}$ PNU120596 reinstated cocaine seeking.

Cue-induced reinstatement. Reintroduction of responsedependent visual and interoceptive/injection-related cues that had previously been associated with cocaine reinstated extinguished cocaine seeking (Figure $5 \mathrm{~d}$ ). Pretreatment with Ro $61-8048(20 \mathrm{mg} / \mathrm{kg})$ significantly decreased cue-induced reinstatement (Figure 5d: $\mathrm{F}_{6,12}=58.68, p<0.001$ ). This effect of Ro 61-8048 was reversed by pretreatment with PNU120596 (1 mg/kg). PNU120596 (1 mg/kg) alone did not affect cue-induced reinstatement of nicotine seeking. Neither Ro 61-8048 (20 mg/kg) nor PNU120596 (1 mg/kg) reinstated extinguished drug seeking when injected before an extinction session.

\section{Effect of Ro 61-8048 on Nicotine-Induced Dopamine Release in the Rat NAcS}

Basal levels of extracellular dopamine, expressed as fmoles per $10 \mu \mathrm{l}$, were as follows: vehicle+vehicle+nicotine group: $18.3 \pm 4.1$; vehicle+Ro+nicotine group: $30.0 \pm 5.1$; PNU+Ro +nicotine group: $20.3 \pm 4.7$; PNU+vehicle+nicotine group: $26.0 \pm 4.6 ; \quad \mathrm{PNU}+$ vehicle+vehicle group: $32.8 \pm 8.7 ;$ and vehicle+Ro+vehicle group: $24.0 \pm 6.5$. Nicotine $(0.4 \mathrm{mg} / \mathrm{kg}$, s.c.) increased extracellular dopamine levels by $\sim 2.4$-fold compared with basal levels (Figure 6; $\mathrm{F}_{9,72}=10.31$, $p<0.001)$. Ro $61-8048(100 \mathrm{mg} / \mathrm{kg}$, i.p. $)$ did not alter dopamine levels when given alone (ie, with the vehicles of PNU120596 or nicotine), but significantly reduced the ability of nicotine to elevate dopamine levels (Figure 6; two-way ANOVA; treatment effect: $\left.\mathrm{F}_{(3,390)}=27.11, \quad p<0.001\right)$. PNU120596 (1 mg/kg, i.p.) did not affect extracellular dopamine levels when given alone, nor did it alter the effects of nicotine or the ability of Ro $61-8048(100 \mathrm{mg} / \mathrm{kg})$ to block the effects of nicotine. At a higher dose ( $3 \mathrm{mg} / \mathrm{kg}$ i.p.), PNU120596 significantly increased dopamine levels in this area (Figure 6 inset; $\mathrm{F}_{9,36}=6.10, p<0.0001$ ).

\section{DISCUSSION}

The present study shows that systemic administration of the KMO inhibitor Ro 61-8048 effectively reduces the reinforcing effects of nicotine and blocks the relapse-like effects induced by reexposure to nicotine and nicotine-associated cues after a period of abstinence in rats and squirrel monkeys. Attenuation of the reinforcing effects of nicotine in monkeys was clearly demonstrated by downward shifts of the dose-response functions. These findings extend our earlier findings that Ro 61-8048 reduces cannabinoid selfadministration and blocks the reinstatement of cannabinoid seeking (Justinova et al, 2013). The effects of Ro 61-8048 
a

Cocaine self-administration

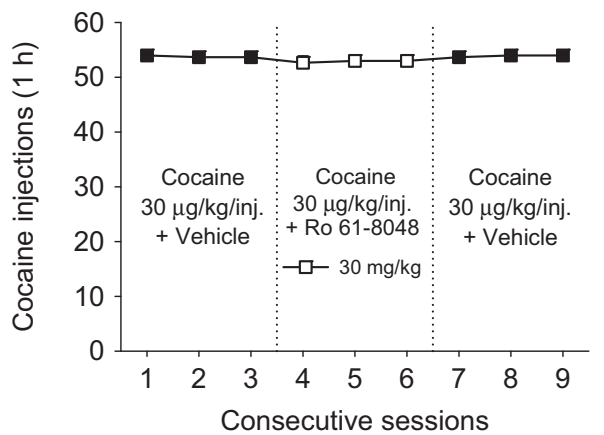

C

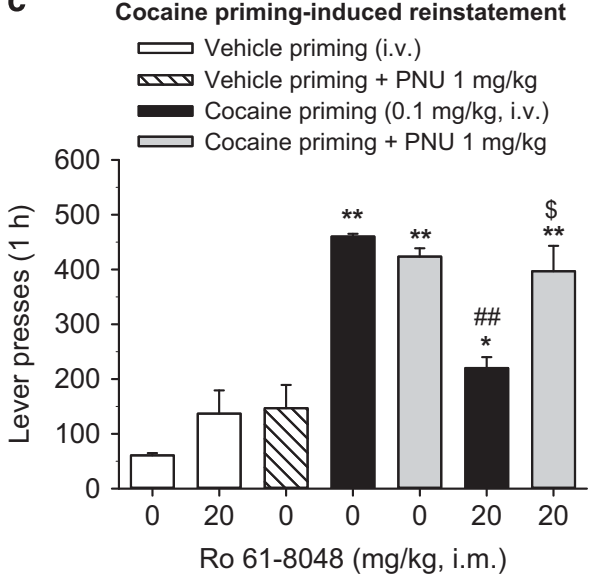

b

Cocaine self-administration

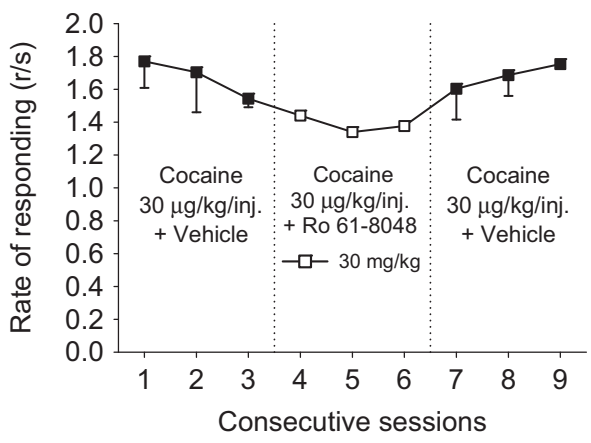

d

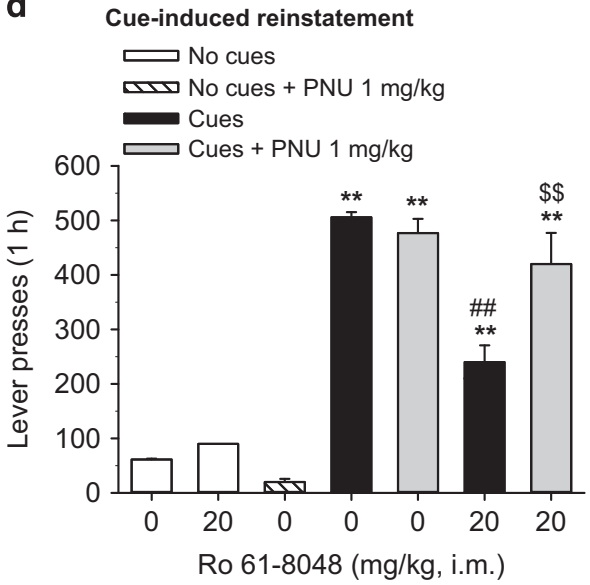

Figure 5 Ro 6I-8048 does not affect cocaine self-administration under FRI 0 schedule, but blocks reinstatement of extinguished cocaine seeking in squirrel monkeys. (a, b) The 3-day treatment with Ro $61-8048$ (30 mg/ $\mathrm{kg}$, i.m., 40 min before sessions 4-6) had no effect on the number of cocaine (30 $\mathrm{kg} / / \mathrm{kg}$ ) injections self-administered during I h sessions (a) and the overall response rate (b). (c, d) Vehicle (0 mg/kg), Ro 6I-8048 (20 mg/kg), and PNUI20596 $(\mathrm{l} \mathrm{mg} / \mathrm{kg})$ were administered alone or in combination before: priming with vehicle or cocaine $(0.1 \mathrm{mg} / \mathrm{kg})$ i.v. injection (c) or reintroduction of cocaineassociated cues (d). 'Vehicle priming+0 mg/kg Ro 6I-8048' and 'No cues+0 mg/kg Ro 61-8048' bars represent the average of 5-7 extinction sessions preceding the test sessions. 'Cocaine priming+0 mg/kg Ro 6I-8048' bars represent the average from two tests. 'Cues+0 mg/kg Ro 6 I-8048' bars represent the average from three tests. *Significantly different from 'Vehicle priming+0 mg/kg Ro 6I-8048' or 'No cues+0 mg/kg Ro 61-8048'; \# significantly different from 'Cocaine priming+0 mg/kg Ro 61-8048' or 'Cues+0 mg/kg Ro 61-8048'; \$significantly different from 'Cocaine priming+20 mg/kg Ro 6I-8048' or 'Cues +20 mg/kg Ro 6I-8048', Tukey's test, * or $\$ p<0.05$, *** or ${ }^{\# \#}$ or $\$ \$ p<0.01$. The symbols and bars represent means \pm SEM ( $n=3$ in all parts of the Figure). PNU, PNUI 20596.

were selective for nicotine reinforcement, as it did not decrease operant responding for cocaine or food (Justinova et al, 2013) under the same conditions in monkeys or nonreinforced (inactive-hole) responding in rats. Furthermore, the current study shows that Ro 61-8048 is effective in reducing priming and cue-induced reinstatement of cocaine seeking in monkeys. Together, these findings suggest that KMO inhibition could be an effective therapeutic approach to preventing drug seeking and relapse, and that it applies to more than one class of drugs. As pharmacological treatment of drug dependence remains a major challenge (Kenna et al, 2007), and as polydrug use is commonly seen in addicted individuals, it could be particularly advantageous to develop medications that effectively attenuate the reinforcing effects of multiple drugs and/or block the relapse-inducing effects of cues related to drugs from multiple pharmacological classes.

Ro 61-8048 substantially reduced nicotine selfadministration at all doses tested $(10-30 \mathrm{mg} / \mathrm{kg})$ in monkeys. The $20 \mathrm{mg} / \mathrm{kg}$ dose was chosen for testing in relapse models and for reversal experiments assessing the role of $\alpha 7 \mathrm{nAChRs}$ in the effects of Ro 61-8048 because this dose consistently reduced nicotine self-administration over multiple days of testing in the present study and it significantly shifted nicotine dose-response functions downward. Ro 61-8048 also completely counteracted the behavioral effects of THC in monkeys in our previous study (Justinova et al, 2013). In the present study, Ro 61-8048 prevented relapse-like effects that were triggered by reexposure to nicotine itself or to nicotine-associated cues, even though these relapse-like effects are believed to involve distinct brain circuits (Bossert et al, 2013).

Notably, $\alpha 7 \mathrm{nAChRs}$ were clearly implicated in the ability of Ro 61-8048 to decrease nicotine reinforcement and relapse in monkeys because these effects were prevented by administration of PNU120596, a selective positive allosteric modulator that binds to the same allosteric $\alpha 7 \mathrm{nAChR}$ site where KYNA acts as a negative allosteric modulator (Lopes et al, 2007). However, the effects of Ro 61-8048 on nicotine self-administration and reinstatement were not reversed by PNU120596 in rats, suggesting the possibility that these effects might not be 


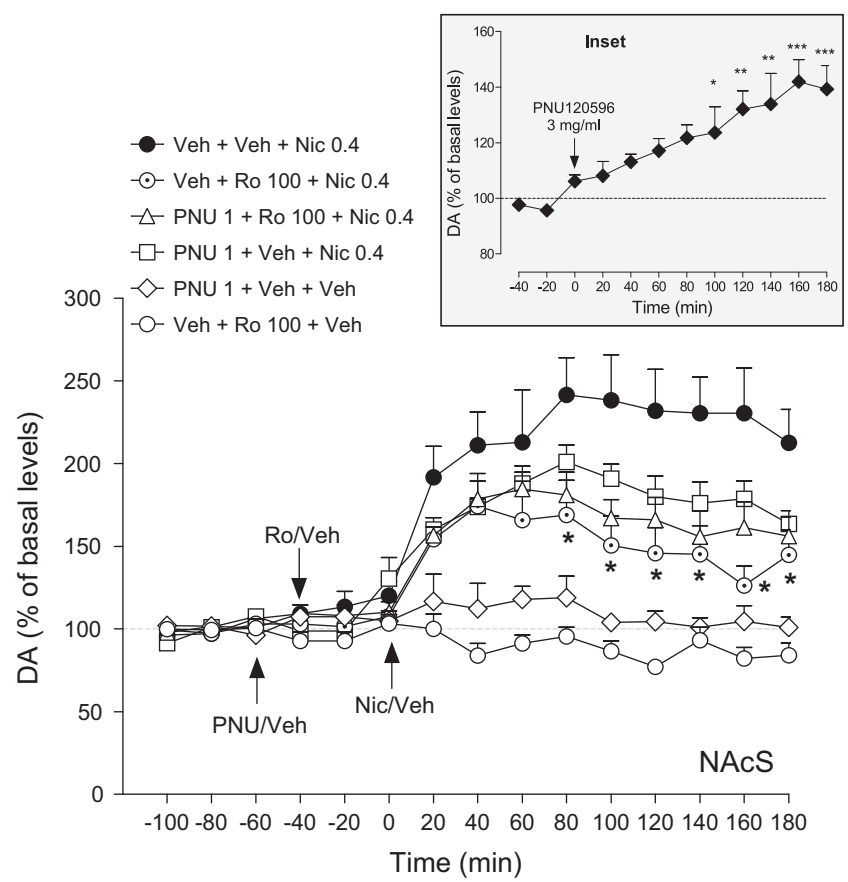

Figure 6 Ro 6I-8048 decreases nicotine-induced elevations of extracellular dopamine levels in the nucleus accumbens shell (NAcS) in freely moving rats. Pretreatment with Ro 6I-8048 (I 00 mg/kg, i.p., 'Veh+Ro I 00 +Nic 0.4', dotted circles, $n=8$ ) but not vehicle ('Veh+Veh+Nic 0.4', filled circles, $n=9) 40 \mathrm{~min}$ before nicotine $(0.4 \mathrm{mg} / \mathrm{kg}$, s.c.) significantly reduced the increase in extracellular dopamine levels induced by nicotine in the NAcS. PNUI 20596 ( I mg/kg, i.p.), injected 20 min before Ro 6I-8048 did not reverse this effect (PNU I+Ro $100+N i c$ 0.4, triangles, $n=7$ ). Neither Ro 6I-8048 (I00 mg/kg, 'Veh+Ro I00+Veh', open circles, $n=6)$ nor PNUI20596 ( I mg/kg, 'PNU I+Veh+Veh', open diamonds, $n=5)$ altered dopamine levels when given together with appropriate vehicles. PNUI20596 (I mg/kg, 'PNU I+Veh+Nic 0.4, squares, $n=6$ ) did not significantly lower nicotine-induced dopamine elevations in the NAcS. Inset: dopamine levels in the NAcS after an injection of PNUI 20596 at a dose $3 \mathrm{mg} / \mathrm{kg}$ (i.p., $n=5$ ). Basal levels of extracellular dopamine, expressed as fmoles per $10 \mu$, were: vehicle+vehicle+nicotine: $18.3 \pm 4.1$; vehicle+Ro +nicotine: $30.0 \pm 5.1$; PNU+Ro+nicotine: $20.3 \pm 4.7$; PNU+vehicle+nicotine: $26.0 \pm 4.6$; PNU+vehicle+vehicle: $32.8 \pm 8.7$; and vehicle+Ro+vehicle: $24.0 \pm 6.5$. All symbols represent means \pm SEM and dopamine (DA) levels are expressed as a percentage of basal levels over time. *Significantly different from the Veh+Veh+Nic 0.4 combination or baseline dopamine levels (inset), Tukey's test, ${ }^{*} p<0.05, * * p<0.0$ I, $* * * * 0<0.00$ I. Arrows indicate time of injection. Veh, vehicle; Nic, nicotine; Ro, Ro 6I-8048; PNU, PNUI 20596.

mediated by $\alpha 7 \mathrm{nAChRs}$. Species-related differences could potentially arise from the fact that KYNA concentrations in the brain are much higher in primates (including humans) than in rodents (Moroni et al, 1988; Turski et al, 1988). Considering that KYNA is not only a negative allosteric modulator of $\alpha 7 \mathrm{nAChRs}$ but can also act as a competitive antagonist of the glycine co-agonist site of the NMDA receptor and affect AMPA and kainate receptors at high concentrations (Bertolino et al, 1989; Hilmas et al, 2001; Kessler et al, 1989; Prescott et al, 2006), there could be differential involvement of these receptor mechanisms across species.

It is well known that nicotine elevates extracellular levels of dopamine in the rat NAcS, an effect that is mediated by nicotinic receptors and presumably underlies the rewarding and dependence-inducing effects of tobacco (Corrigall $e t$ al,
1994; Dani and Bertrand, 2007; Picciotto et al, 1998). Ro 618048 increases extracellular levels of KYNA in the NAcS and VTA of rats (Justinova et al, 2013) and, as shown here, Ro 61-8048 reduces the ability of nicotine to stimulate dopamine release in the NAcS. However, this effect of Ro 61-8048 was not reversed by PNU120596, and hence in both the dialysis and behavioral experiments it could not be established that the blockade of nicotine effect by Ro 61-8048 in rats is mediated by $\alpha 7 \mathrm{nAChRs}$. This finding with nicotine contrasts with our earlier finding that the same dose of PNU120596 $(1 \mathrm{mg} / \mathrm{kg}$ ) completely reverses the effects of Ro 61-8048 on THC-induced accumbal dopamine release (Justinova et al, 2013). A possible explanation for this difference is that negative allosteric modulation is harder to disrupt in the case of nicotine that directly affects $\alpha 7 \mathrm{nAChRs}$, as opposed to THC that does not. Unfortunately, higher doses of PNU120596 are not suitable for reversal tests in rats because they significantly increase accumbal dopamine release when given alone.

Cocaine self-administration in monkeys was not affected by a $30 \mathrm{mg} / \mathrm{kg}$ dose of Ro 61-8048, consistent with our earlier finding that it was not affected by a $20 \mathrm{mg} / \mathrm{kg}$ dose (Justinova et al, 2013). Therefore, it is surprising that in the present study $20 \mathrm{mg} / \mathrm{kg}$ of Ro $61-8048$ blocked the reinstatement of cocaine seeking in both the cocaine priming and the cue reexposure experiments. The effects of Ro 61-8048 were quite similar in the models of cocaine and nicotine relapse, suggesting that KMO inhibition has potential for protecting against relapse to use of not only nicotine, cannabis, and cocaine, but possibly to other drugs or even coabused drugs. Testing with PNU120596 indicated that $\alpha 7 \mathrm{nAChRs}$ may be involved in the effects of Ro 61-8048 on reinstatement of cocaine seeking in monkeys. Importantly, Ro 61-8048 alone did not reinstate extinguished nicotine or cocaine seeking in monkeys, suggesting it is unlikely to induce relapse. Cocainerelated effects of KYNA have not been studied extensively, but it is known that intra-VTA administration of KYNA in a micromolar or millimolar range of doses decreases cocaineprimed reinstatement in rats by acting as a nonselective antagonist of ionotropic glutamate receptors (Sun et al, 2005; Wise et al, 2008).

\section{CONCLUSION}

The present results suggest that KMO inhibition could be an effective new approach for the treatment of tobacco dependence. Specifically, it could be beneficial for both the induction of abstinence from tobacco and the prevention of relapse. Furthermore, it could counteract two major triggers of relapse, reexposure to nicotine (eg, through second-hand smoke) and smoking-related environmental cues. Tobacco smoking is highly prevalent among users of cannabis or cocaine (Agrawal et al, 2012; Budney et al, 1993), and our current and previous (Justinova et al, 2013) results indicate that $\mathrm{KMO}$ inhibition is effective in preventing reinstatement of drug seeking triggered by nicotine, cocaine, THC, or cues associated with taking these drugs. Thus, KMO inhibition might be particularly helpful for relapse prevention in individuals who use more than one of these drugs. The effects obtained here in nonhuman primates were likely mediated by KYNA actions as a negative allosteric modulator 
of $\alpha 7 \mathrm{nAChRs}$. However, the effects of KMO inhibition in rats were not reversed by a positive allosteric modulator of $\alpha 7$ nAChRs in this study, and as a result the underlying mechanism in rats is not clear. As KYNA can also act at other receptor systems in the brain (Bertolino et al, 1989; Kessler et al, 1989; Prescott et al, 2006; see Moroni et al, 2012, for review), it is possible that some of the effects observed here involve additional molecular targets. Of note, $\mathrm{KMO}$ inhibitors are currently being developed as treatments for neurodegenerative disorders such as Huntington's, Alzheimer's, and Parkinson's diseases (Amaral et al, 2013; Smith et al, 2016). Progress in these areas might therefore facilitate the application of KMO inhibition to the treatment of addiction.

\section{FUNDING AND DISCLOSURE}

This study was supported by the Intramural Research Program of the National Institute on Drug Abuse, National Institutes of Health. Dr Robert Schwarcz was supported by NIMH grant P50 MH103222. The authors declare no conflict of interest.

\section{ACKNOWLEDGMENTS}

We dedicate this study to Dr Steven R Goldberg (died on 25 November 2014). We thank Dr Ira Baum and Philip White for their excellent veterinary assistance during the primate studies.

\section{REFERENCES}

Agrawal A, Budney AJ, Lynskey MT (2012). The co-occurring use and misuse of cannabis and tobacco: a review. Addiction 107: 1221-1233.

Amaral M, Outeiro TF, Scrutton NS, Giorgini F (2013). The causative role and therapeutic potential of the kynurenine pathway in neurodegenerative disease. J Mol Med (Berl) 91: 705-713.

Amori L, Wu HQ, Marinozzi M, Pellicciari R, Guidetti P, Schwarcz R (2009). Specific inhibition of kynurenate synthesis enhances extracellular dopamine levels in the rodent striatum. Neuroscience 159: 196-203.

Baran H, Jellinger K, Deecke L (1999). Kynurenine metabolism in Alzheimer's disease. J Neural Transm 106: 165-181.

Beal MF, Matson WR, Swartz KJ, Gamache PH, Bird ED (1990). Kynurenine pathway measurements in Huntington's disease striatum: evidence for reduced formation of kynurenic acid. J Neurochem 55: 1327-1339.

Beggiato S, Antonelli T, Tomasini MC, Tanganelli S, Fuxe K, Schwarcz R et al (2013). Kynurenic acid, by targeting alpha7 nicotinic acetylcholine receptors, modulates extracellular GABA levels in the rat striatum in vivo. Eur J Neurosci 37: 1470-1477.

Benowitz NL (2009). Pharmacology of nicotine: addiction, smoking-induced disease, and therapeutics. Annu Rev Pharmacol Toxicol 49: 57-71.

Bertolino M, Vicini S, Costa E (1989). Kynurenic acid inhibits the activation of kainic and $\mathrm{N}$-methyl-D-aspartic acid-sensitive ionotropic receptors by a different mechanism. Neuropharmacology 28: 453-457.

Bossert JM, Marchant NJ, Calu DJ, Shaham Y (2013). The reinstatement model of drug relapse: recent neurobiological findings, emerging research topics, and translational research. Psychopharmacology (Berl) 229: 453-476.
Brunzell DH, McIntosh JM (2012). Alpha7 nicotinic acetylcholine receptors modulate motivation to self-administer nicotine: implications for smoking and schizophrenia. Neuropsychopharmacology 37: 1134-1143.

Budney AJ, Higgins ST, Hughes JR, Bickel WK (1993). Nicotine and caffeine use in cocaine-dependent individuals. J Subst Abuse 5: 117-130.

Carpenedo R, Pittaluga A, Cozzi A, Attucci S, Galli A, Raiteri M et al (2001). Presynaptic kynurenate-sensitive receptors inhibit glutamate release. Eur J Neurosci 13: 2141-2147.

Corrigall WA, Coen KM, Adamson KL (1994). Self-administered nicotine activates the mesolimbic dopamine system through the ventral tegmental area. Brain Res 653: 278-284.

Dani JA, Bertrand D (2007). Nicotinic acetylcholine receptors and nicotinic cholinergic mechanisms of the central nervous system. Annu Rev Pharmacol Toxicol 47: 699-729.

Erhardt S, Blennow K, Nordin C, Skogh E, Lindstrom LH, Engberg G (2001). Kynurenic acid levels are elevated in the cerebrospinal fluid of patients with schizophrenia. Neurosci Lett 313: 96-98.

Erhardt S, Hajos M, Lindberg A, Engberg G (2000). Nicotine-induced excitation of locus coeruleus neurons is blocked by elevated levels of endogenous kynurenic acid. Synapse 37: 104-108.

Foster AC, Vezzani A, French ED, Schwarcz R (1984). Kynurenic acid blocks neurotoxicity and seizures induced in rats by the related brain metabolite quinolinic acid. Neurosci Lett 48: 273-278.

Goldberg SR, Spealman RD, Goldberg DM (1981). Persistent behavior at high rates maintained by intravenous self-administration of nicotine. Science 214: 573-575.

Harvey DM, Yasar S, Heishman SJ, Panlilio LV, Henningfield JE, Goldberg SR (2004). Nicotine serves as an effective reinforcer of intravenous drug-taking behavior in human cigarette smokers. Psychopharmacology (Berl) 175: 134-142.

Hilmas C, Pereira EF, Alkondon M, Rassoulpour A, Schwarcz R, Albuquerque EX (2001). The brain metabolite kynurenic acid inhibits alpha7 nicotinic receptor activity and increases nonalpha7 nicotinic receptor expression: physiopathological implications. J Neurosci 21: 7463-7473.

Hurst RS, Hajos M, Raggenbass M, Wall TM, Higdon NR, Lawson JA et al (2005). A novel positive allosteric modulator of the alpha7 neuronal nicotinic acetylcholine receptor: in vitro and in vivo characterization. J Neurosci 25: 4396-4405.

Jackson KJ, Martin BR, Changeux JP, Damaj MI (2008). Differential role of nicotinic acetylcholine receptor subunits in physical and affective nicotine withdrawal signs. J Pharmacol Exp Ther 325: 302-312.

Justinova Z, Mascia P, Wu HQ, Secci ME, Redhi GH, Panlilio LV et al (2013). Reducing cannabinoid abuse and preventing relapse by enhancing endogenous brain levels of kynurenic acid. Nat Neurosci 16: 1652-1661.

Justinova Z, Tanda G, Redhi GH, Goldberg SR (2003). Selfadministration of delta9-tetrahydrocannabinol (THC) by drug naive squirrel monkeys. Psychopharmacology 169: 135-140.

Kenna GA, Nielsen DM, Mello P, Schiesl A, Swift RM (2007). Pharmacotherapy of dual substance abuse and dependence. CNS Drugs 21: 213-237.

Kessler M, Terramani T, Lynch G, Baudry M (1989). A glycine site associated with N-methyl-D-aspartic acid receptors: characterization and identification of a new class of antagonists. J Neurochem 52: 1319-1328.

Kiss C, Ceresoli-Borroni G, Guidetti P, Zielke CL, Zielke HR, Schwarcz R (2003). Kynurenate production by cultured human astrocytes. J Neural Transm 110: 1-14.

Konradsson-Geuken A, Gash CR, Alexander K, Pomerleau F, Huettl P, Gerhardt GA et al (2009). Second-by-second analysis of alpha 7 nicotine receptor regulation of glutamate release in the prefrontal cortex of awake rats. Synapse 63: 1069-1082.

Koshy Cherian A, Gritton H, Johnson DE, Young D, Kozak R, Sarter M (2014). A systemically-available kynurenine aminotransferase II (KAT II) inhibitor restores nicotine-evoked 
glutamatergic activity in the cortex of rats. Neuropharmacology 82: $41-48$

Levin ED, Petro A, Rezvani AH, Pollard N, Christopher NC, Strauss M et al (2009). Nicotinic alpha7- or beta2-containing receptor knockout: effects on radial-arm maze learning and long-term nicotine consumption in mice. Behav Brain Res 196: 207-213.

Liu X (2014). Effects of blockade of alpha4beta2 and alpha7 nicotinic acetylcholine receptors on cue-induced reinstatement of nicotine-seeking behaviour in rats. Int J Neuropsychopharmacol 17: 105-116.

Lopes C, Pereira EF, Wu HQ, Purushottamachar P, Njar V, Schwarcz $\mathrm{R}$ et al (2007). Competitive antagonism between the nicotinic allosteric potentiating ligand galantamine and kynurenic acid at alpha7* nicotinic receptors. J Pharmacol Exp Ther 322: $48-58$.

Markou A, Paterson NE (2001). The nicotinic antagonist methyllycaconitine has differential effects on nicotine self-administration and nicotine withdrawal in the rat. Nicotine Tob Res 3: 361-373.

Mascia P, Pistis M, Justinova Z, Panlilio LV, Luchicchi A, Lecca S et al (2011). Blockade of nicotine reward and reinstatement by activation of alpha-type peroxisome proliferator-activated receptors. Biol Psychiatry 69: 633-641.

Moroni F, Cozzi A, Sili M, Mannaioni G (2012). Kynurenic acid: a metabolite with multiple actions and multiple targets in brain and periphery. J Neural Transm 119: 133-139.

Moroni F, Russi P, Lombardi G, Beni M, Carlà V (1988). Presence of kynurenic acid in the mammalian brain. J Neurochem 51: $177-180$.

Orejarena MJ, Herrera-Solis A, Pons S, Maskos U, Maldonado R, Robledo P (2012). Selective re-expression of beta2 nicotinic acetylcholine receptor subunits in the ventral tegmental area of the mouse restores intravenous nicotine self-administration. Neuropharmacology 63: 235-241.

Paxinos G, Watson C (2005). The rat brain in stereotaxic coordinates. 5th edn. Elsevier Academic Press: Amsterdam.

Perkins MN, Stone TW (1982). An iontophoretic investigation of the actions of convulsant kynurenines and their interaction with the endogenous excitant quinolinic acid. Brain Res 247: 184-187.

Picciotto MR, Zoli M, Rimondini R, Lena C, Marubio LM, Pich EM et al (1998). Acetylcholine receptors containing the beta2 subunit are involved in the reinforcing properties of nicotine. Nature 391: 173-177.

Prescott C, Weeks AM, Staley KJ, Partin KM (2006). Kynurenic acid has a dual action on AMPA receptor responses. Neurosci Lett 402: 108-112.

Rassoulpour A, Wu HQ, Albuquerque EX, Schwarcz R (2005a). Prolonged nicotine administration results in biphasic, brainspecific changes in kynurenate levels in the rat. Neuropsychopharmacology 30: 697-704.

Rassoulpour A, Wu HQ, Ferré S, Schwarcz R (2005b). Nanomolar concentrations of kynurenic acid reduce extracellular dopamine levels in the striatum. J Neurochem 93: 762-765.

Rose JE, Corrigall WA (1997). Nicotine self-administration in animals and humans: similarities and differences. Psychopharmacology 130: 28-40.
Röver S, Cesura AM, Huguenin P, Kettler R, Szente A (1997). Synthesis and biochemical evaluation of N-(4-phenylthiazol-2-yl) benzenesulfonamides as high-affinity inhibitors of kynurenine 3-hydroxylase. J Med Chem 40: 4378-4385.

Scherma M, Panlilio LV, Fadda P, Fattore L, Gamaleddin I, Le Foll $B$ et al (2008). Inhibition of anandamide hydrolysis by cyclohexyl carbamic acid 3'-carbamoyl-3-yl ester (URB597) reverses abuserelated behavioral and neurochemical effects of nicotine in rats. J Pharmacol Exp Ther 327: 482-490.

Schwarcz R, Rassoulpour A, Wu HQ, Medoff D, Tamminga CA, Roberts RC (2001). Increased cortical kynurenate content in schizophrenia. Biol Psychiatry 50: 521-530.

Shoaib M (2006). Effects of isoarecolone, a nicotinic receptor agonist in rodent models of nicotine dependence. Psychopharmacology (Berl) 188: 252-257.

Smith JR, Jamie JF, Guillemin GJ (2016). Kynurenine-3-monooxygenase: a review of structure, mechanism, and inhibitors. Drug Discov Today 21: 315-324.

Solinas M, Justinova Z, Goldberg SR, Tanda G (2006). Anandamide administration alone and after inhibition of fatty acid amide hydrolase (FAAH) increases dopamine levels in the nucleus accumbens shell in rats. J Neurochem 98: 408-419.

Stone TW, Darlington LG (2013). The kynurenine pathway as a therapeutic target in cognitive and neurodegenerative disorders. Br J Pharmacol 169: 1211-1227.

Sun W, Akins CK, Mattingly AE, Rebec GV (2005). Ionotropic glutamate receptors in the ventral tegmental area regulate cocaine-seeking behavior in rats. Neuropsychopharmacology 30: 2073-2081.

Tapper AR, McKinney SL, Nashmi R, Schwarz J, Deshpande P, Labarca $C$ et al (2004). Nicotine activation of alpha4* receptors: sufficient for reward, tolerance, and sensitization. Science 306: 1029-1032.

Turski WA, Nakamura M, Todd WP, Carpenter BK, Whetsell WO Jr, Schwarcz R (1988). Identification and quantification of kynurenic acid in human brain tissue. Brain Res 454: 164-169.

Wise RA, Wang B, You ZB (2008). Cocaine serves as a peripheral interoceptive conditioned stimulus for central glutamate and dopamine release. PLoS ONE 3: e2846.

Wooltorton JR, Pidoplichko VI, Broide RS, Dani JA (2003). Differential desensitization and distribution of nicotinic acetylcholine receptor subtypes in midbrain dopamine areas. J Neurosci 23: 3176-3185.

Wu HQ, Pereira EF, Bruno JP, Pellicciari R, Albuquerque EX, Schwarcz R (2010). The astrocyte-derived alpha7 nicotinic receptor antagonist kynurenic acid controls extracellular glutamate levels in the prefrontal cortex. J Mol Neurosci 40: 204-210.

Zielinska E, Kuc D, Zgrajka W, Turski WA, Dekundy A (2009). Long-term exposure to nicotine markedly reduces kynurenic acid in rat brain in vitro and ex vivo evidence. Toxicol Appl Pharmacol 240: 174-179.

Zmarowski A, Wu HQ, Brooks JM, Potter MC, Pellicciari R, Schwarcz R et al (2009). Astrocyte-derived kynurenic acid modulates basal and evoked cortical acetylcholine release. Eur $J$ Neurosci 29: 529-538. 